\title{
Middle Eastern Immigrants' Satisfaction With Malaysian Healthcare
}

\author{
Haliyana Khalid \\ Universiti Teknologi Malaysia, Malaysia \\ University of Business and Technology, Jeddah, KSA \\ Mohamad Saleem Anis \\ Universiti Teknologi Malaysia \\ Adriana Mohd Rizal \\ Universiti Teknologi Malaysia, Malaysia \\ University of Business and Technology, Jeddah, KSA
}

Received: October 17, 2021 Accepted: November 12, 2021 Published: November 13, 2021

doi:10.5296/bms.v12i2.19103ＵRL: https://doi.org/10.5296/bms.v12i2.19103

\begin{abstract}
There has been an increasing number of Middle Eastern immigrants arriving in Malaysia over the last decade due to political and economic instability in their countries. Given their somewhat ambiguous living conditions and residence status here (e.g. legal, illegal, refugee, etc.), it is imperative to understand their situation in-depth. One of the most important aspects that impact the living conditions of these immigrants is health; accordingly, in this research, we attempted to discover the extent and factors of Middle Eastern immigrants' satisfaction with the Malaysian healthcare system and its facilities. In this cross-sectional study, we used a questionnaire to collect data from 219 respondents both online and in-person. Various statistical methods were employed to analyze the data, including descriptive analysis, Pearson's correlation, and multiple regression. The findings indicate a slight dissatisfaction among Middle Eastern immigrants with respect to the Malaysian healthcare system, due to the cost of health services and communication barriers. The results also highlight that marital status, monthly income, awareness of services, Malay language proficiency, and culture are
\end{abstract}


factors that impact immigrants' perception of the quality of healthcare services. Therefore, this study provides valuable insights into this important group of immigrants in terms of their experience in public and private healthcare facilities that shape their opinions and satisfaction with the Malaysian healthcare system.

Keywords: immigrants, healthcare management, healthcare, minority

\section{Introduction}

Migration is nothing new in societies; it is as old as humanity. The continued rapid rise in migration worldwide in recent years has led to an increase in the number of international immigrants from 173 million in 2000 to 258 million in 2017, of which over 80 million live in Asia (United Nations, 2018). This is due to many reasons, the most important of which is immigrants' quest to move away from conflict and seek new opportunities in education or work in countries with more political and economic stability (Dontsov \& Zotova, 2013).

Today, Malaysia represents a good example of a stable country. It is thus one of the most attractive countries for immigrants, exemplified by the high number of international immigrants (i.e. 3.4 million), who make up $10.7 \%$ of the population (United Nations, 2019). In the past few years, some changes in the nationality of immigrants are observable in Malaysia. Specifically, there is a growing proportion of arrivals from the Middle East, especially Arab countries, mainly as a result of political and economic unrest in the region. Although many Middle Eastern immigrants hold residence statuses as students or foreign workers, unfortunately, many of them have not been able to obtain formal residence status from the Malaysian government, ultimately becoming refugees or illegal residents. As of October 2020, there were more than 178,000 asylum seekers and refugees registered with UNHCR in Malaysia, including 3,660 Yemenis, 3,250 Syrians, 3,230 Somalis, 1,220 Iraqis, and 750 Palestinians (United Nations High Commissioner for Refugees, 2020).

Healthcare is undoubtedly one of the most important aspects of living abroad for foreigners; as such, their understanding of the local healthcare system and the use of health facilities in the host country is crucial. Immigrants who flee their country due to political unrest or conflict are likely to suffer poorer health and less satisfaction compared to their new host community. This is often a result of bad experiences when leaving their home country (Gagnon, Merry \& Robinson, 2001) or limited access to healthcare in their home country (Grove \& Zwi, 2006). In addition, immigrants often lack the basic information and mobility skills required to keep up with the healthcare system in the new country, which are obstacles made worse by language difficulties, low levels of education, and different health and cultural beliefs (Small et al., 2014; Kreps \& Sparks, 2008).

From an economic point of view, immigrants are potential clients for public and private health facilities (e.g. hospitals, health insurance companies, and pharmacies); thus, the satisfaction of these clients is clearly important. Therefore, understanding the critical factors and challenges that affect the maximum benefit of both parties is an urgent necessity to elicit the satisfaction required to achieve the best possible profit. 
The transition of an individual into a new environment is not easy because of the different social and cultural landscape, which brings with it obstacles such as language and traditions. Such obstacles may affect the immigrant's accessibility to and satisfaction with healthcare services in the new country. It is thus essential to have an in-depth understanding of the extent of Middle Eastern immigrants' satisfaction with Malaysian healthcare services, both public and private, as well as the key reasons influencing their opinions, to create a reference that can be useful for healthcare business managers. This would give them the opportunity to take quick and effective measures to achieve their healthcare organization's main aim of providing patient satisfaction by taking account of this client group's special traits (e.g. cultural differences, language barrier, lack of information, mobility issues).

In addition, in the healthcare sector, the interaction with patients is always at a high level. Consequently, the degree of satisfaction has important indications and implications for clients' future decisions. For example, one study showed that patient satisfaction affects consumer behavior in terms of positive comments, preference for specific medical centers, increased number of visits, and willingness to pay for a service even at a higher cost (Zeithaml \& Bitner, 2000).

On the other hand, it is not only the private sector of the healthcare industry that should be concerned about understanding these immigrants. Malaysian governmental organizations in the health sector are also in the same boat in terms of the need to pay attention to immigrants' health situation and their satisfaction. This is because it was found that the threat posed by some immigrant groups may reduce the general health level of the country (Carballo \& Nerukar, 2001) due to their deteriorating health status. A lack of awareness about the healthcare system, insufficient language proficiency, and trouble communicating with healthcare providers can all result in differing uses of and satisfaction with the Malaysian healthcare system among immigrants (Moullan \& Jusot, 2014).

Clarifying the extent of understanding and satisfaction of this group of immigrants further enables us to grasp the reality of their health level, which is particularly important because it influences the Malaysian healthcare system as a whole. Indeed, the satisfaction of users is often seen as a key indicator of the quality of healthcare services in any country (Lian, 2005). As such, the poor health level of these immigrants threatens to cause a decline in the overall health level of the country (Carballo \& Nerukar, 2001). However, no previous study in Malaysia has addressed this group of immigrants and their satisfaction with health services. Empirically examining the most important reasons for these immigrants' satisfaction will enable decision-makers to design and implement appropriate measures and policies that help immigrants gain a healthier, better quality life.

Indeed, research shows a divergence in the views of participants according to their nationality and host country. One study found that adolescent immigrants in Europe suffer from many difficulties, including higher suicide attempt rates compared to their peers (McMahon et al., 2017). In central Asia, shocking information emerged about the health status of immigrants, where immigrants to Kazakhstan reported that their health is poor, they do not see a doctor 
when needed, and immigrant women are at higher risk for poor health and lack of access to medical services (Ismayilova et al., 2014). In contrast, another study confirmed that British immigrants are generally satisfied with public healthcare in France, with more than $80 \%$ of respondents stating that their relationship with their doctor is excellent or very good (Pelletier-Fleury \& Le Vaillant, 2013). One research in Sweden confirmed the need for further studies on immigrants, especially older people, as immigrants suffer more health problems in general. Overall, available studies may have different interpretations due to cultural differences, time of residence, social and economic statuses, and the extent of adaptation to the new society (Albin, Albertsson, Ekberg \& Hjelm, 2005). Therefore, it is necessary to take account of past studies from different countries to conduct this study in a realistic manner. Since there has been no previous study on this group of patients in Malaysia, our study has tried to bridge this gap in the literature by exploring satisfaction with Malaysian healthcare services among Middle Eastern illegal and legal immigrants born outside Malaysia.

\section{Method}

This study was a cross-sectional study that employed the survey method to collect quantitative data from Middle Eastern immigrants in both English and Arabic.

\subsection{Sampling}

The target respondents of this study were immigrants from the Middle East who had come to Malaysia on a temporary or long-term basis and were aged 18 years or above at the time of the study. It should be noted that a proportion of them had become refugees or illegal residents due to the difficult humanitarian and economic conditions in their countries of origin. This research not only addressed immigrant patients and their past experiences, but also explored the extent to which immigrants understand and are satisfied with the healthcare system in terms of accessibility and affordability in future situations. This is important because it allows the analysis of potential clients' data that effectively affects both the public and private health sectors. The inclusion criteria for participants in the study were as follows:

1) Persons of either gender (male or female).

2) Persons over the age of 18 .

3) Persons born in the Arab world or Middle East ${ }^{1}$.

4) Persons born to two foreign-born parents and have moved to Malaysia.

1 The Arab states are as follows: Algeria - Bahrain - Comoros - Djibouti - Egypt - Iraq Jordan - Kuwait - Lebanon - Libya Mauritania - Morocco - Oman - Palestine - Qatar - Saudi Arabia - Somalia - Sudan - Syria - Tunisia - United Arab Emirates - Yemen. The countries of the Middle East include some Arab countries in addition to: Iran, Turkey, and Cyprus 
Since there are no official statistics for the number of Middle Eastern immigrants to Malaysia, the minimum sample size taken was 200 , which is an acceptable size for an unknown population at a $95 \%$ confidence level and a precision of $\pm 7 \%$ (Glenn, 1992). The participants were informed about the aims of the study and that their participation would be completely voluntary. Also, they were informed that no personal data will be revealed and the results of the study will be used for publication.

\subsection{Data Collection}

The questionnaire was distributed to the target sample via two methods. The first method was to publish an online questionnaire created using the "Zoho Survey" website on different social media sites. The majority of the data was collected with this method, as it facilitated access to the target respondents at the least possible cost and in the shortest possible time, although it may have produced some undesirable results that were neglected later. The second method involved handing over the questionnaire in person through a wide range of acquaintances, colleagues, and their families and friends. In return for the great effort expended under this approach, it easily provided a clearer and more realistic understanding of the participants' emotions and responses.

The questionnaire was published in two languages, English and Arabic, since the majority of the target population use Arabic as their mother tongue. That made the instrument more capable of getting accurate answers by eliminating the difficulties of understanding a foreign language.

\subsection{Statistical Analysis}

To analyze the survey's results, descriptive statistics were used to summarize and clarify the most important information from the 32-item questionnaire. The measurement of frequency, expressed as percentages, is one way to achieve descriptive analysis. Next, the associations between the dependent variable and independent variables were analyzed using correlation analysis (r) to indicate the strength, direction, and significance of the linear relationships between two variables (Malhotra, 2010). An r value approaching +1 is referred to as a strong positive relationship while a value approaching -1 indicates a strong negative relationship. Specifically, in this study, Pearson's correlation analysis was used.

To further assess the linear relationships between the dependent variable and the multiple independent ones, multiple regression analysis was used. The coefficient of determination value $\left(\mathrm{R}^{2}\right)$ is reported between 0 and 1 , where a higher value indicates the stronger influence of the independent variables on the dependent one. In addition, reliability analysis was performed using Cronbach's alpha. All analyses were conducted with IBM's Statistical Package for the Social Sciences (SPSS) version 24.0 for Windows.

\subsection{Pilot Study}

We conducted a pilot study prior to actual data collection to ensure the clarity and comprehensibility of the questionnaire for the respondents as well as to measure the items' 
internal consistency, expressed as reliability, using Cronbach's alpha. The Cronbach's alpha value is between 0 and 1 , such that a higher number indicates a higher reliability (Boudreau, Gefen \& Straub, 2001). The recommended value for reliability is above 0.7. As reported in Table 1, 30 participants were selected for the pilot study, wherein five answered the questionnaire in English and 25 answered it in Arabic. Half of them answered a paper questionnaire in-person while the other half answered the online version. Those who completed the questionnaire in-person were asked to add their comments on the wordings and questions to help improve the content. The results of the pilot study confirmed that all participants found the questionnaire to be simple and understandable.

Table 1. Participants in Pilot Study

Method of Data collection

No. of Participants in Pilot Study (30)

In person (English Version)

3

In person (Arabic Version) 12

Internet (English Version)

2

Internet (Arabic Version)

13

However, some technical problems emerged with the electronic questionnaire, causing a small number of participants to be unable to complete the survey on their mobile devices. This category was advised to use their computers to avoid this problem. On the other hand, as listed in the Table 2 below, the results of the reliability test indicated a satisfactory Cronbach's alpha value exceeding 0.85 for the 10 -item scale of satisfaction with healthcare services.

Table 2. Reliability Results of Pilot Study

\section{Scale}

Satisfaction Level with Healthcare Services
No. of Items

10
Cronbach's Alpha

0.856

\section{Results}

The final number of respondents reached 233, but the number was reduced to 219 as 14 questionnares had to be excluded due to missing data. Most of the questionnaires were completed online (144) while some were collected in person (89). Table 3 summarizes the data collection figures and methods. 
Table 3. Distribution of Participants

Method of Data Collection

\begin{tabular}{cc} 
Method of Data Collection & $\begin{array}{c}\text { No. of Participants in Study } \\
\mathbf{N = 2 3 3}(\mathbf{N}=\mathbf{2 1 9})\end{array}$ \\
\hline In person (English Version) & $8(8)$ \\
\hline In person (Arabic Version) & $81(80)$ \\
\hline Internet (English Version) & $20(15)$ \\
\hline Internet (Arabic Version) & $124(116)$ \\
\hline
\end{tabular}

\subsection{Reliability Analysis}

The value of Cronbach's alpha is considered acceptable above 0.70 and very good above 0.80 (Pallant, 2011). The value of 0.80 was slightly exceeded (see Table 4 ) based on our reliability analysis of the final data. This indicates high internal consistency of the measurement scale for satisfaction with healthcare services.

Table 4. Reliability results

\section{Reliability Statistics}

Cronbach's Alpha

.802

\author{
$\mathrm{N}$ of Items
}

\subsection{Descriptive Analysis}

\subsubsection{Socioeconomic Background}

The participants' nationalities were within the scope of the study (i.e., from Middle Eastern countries). In particular, they were from 20 countries, with a majority from the Syrian Arab Republic (23\%), followed by Yemen (12.8\%) and Egypt (10.5\%). Table 5 shows the complete information on the respondents' nationalities. 
Table 5. Respondents' Country of Origin

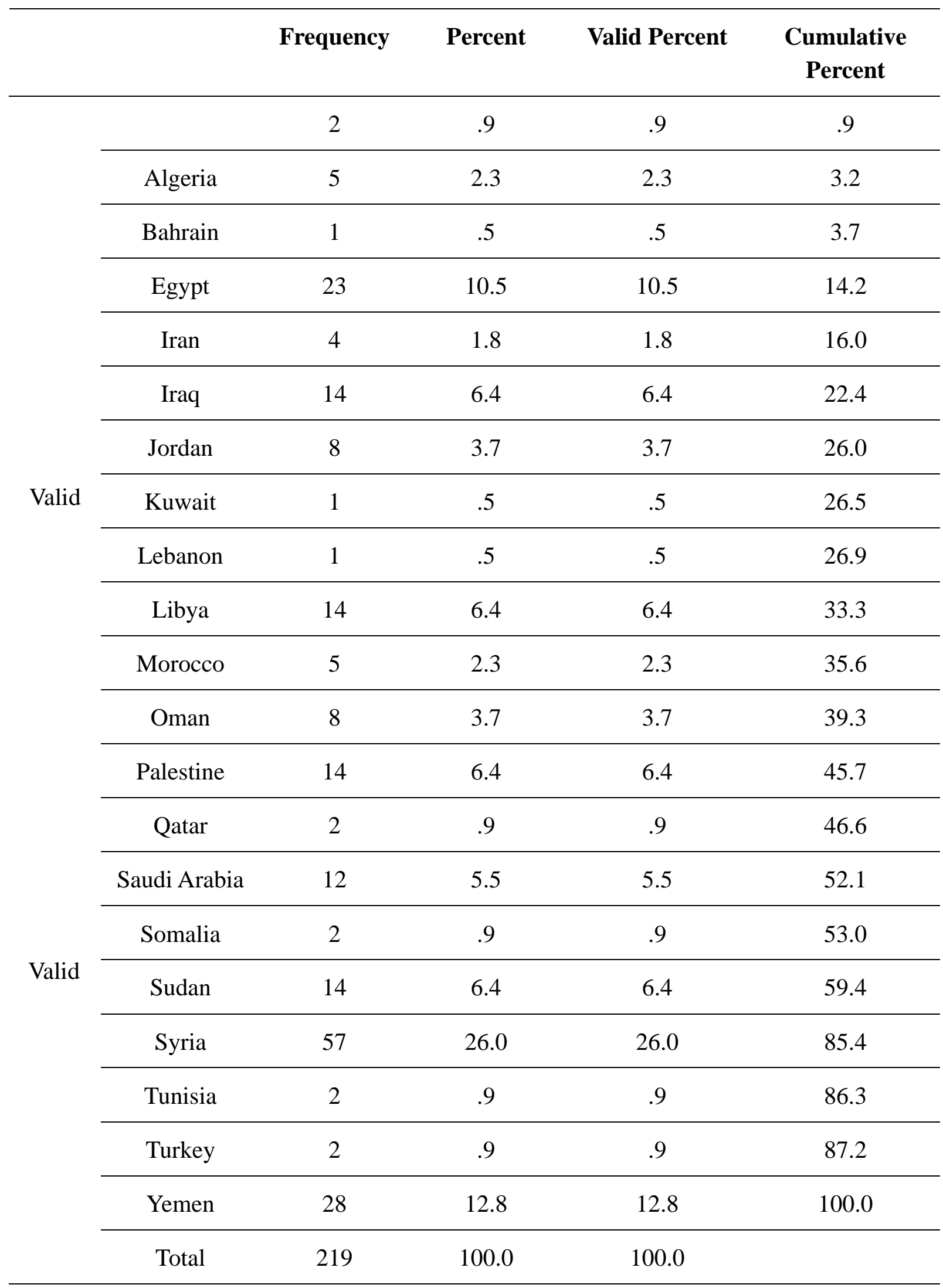


In terms of gender, the number of males $(57.1 \%)$ was slightly higher than the number of females $(42.9 \%)$ who participated in the study (see Table 6).

Table 6. Respondents' Gender

\begin{tabular}{cccccc}
\hline & & Frequency & Percent & Valid Percent & Cumulative Percent \\
\hline \multirow{3}{*}{ Valid } & Male & 125 & 57.1 & 57.1 & 57.1 \\
\cline { 2 - 6 } & Female & 94 & 42.9 & 42.9 & 100.0 \\
\cline { 2 - 6 } & Total & 219 & 100.0 & 100.0 & \\
\hline
\end{tabular}

Next, the age group that was most responsive to the questionnaire was those from 25 to 34 years old $(46.1 \%)$, followed by the younger age group of 18 to 24 years old $(32.7 \%)$ (see Table 7).

Table 7. Respondents' Age

\begin{tabular}{|c|c|c|c|c|c|}
\hline & & Frequency & Percent & Valid Percent & $\begin{array}{c}\text { Cumulative } \\
\text { Percent }\end{array}$ \\
\hline \multirow{6}{*}{ Valid } & 18 to 24 & 71 & 32.4 & 32.7 & 32.7 \\
\hline & 25 to 34 & 101 & 46.1 & 46.5 & 79.3 \\
\hline & 35 to 44 & 37 & 16.9 & 17.1 & 96.3 \\
\hline & 45 to 54 & 5 & 2.3 & 2.3 & 98.6 \\
\hline & 55 to 59 & 3 & 1.4 & 1.4 & 100.0 \\
\hline & Total & 217 & 99.1 & 100.0 & \\
\hline Missing & & 2 & .9 & & \\
\hline & Total & 219 & 100.0 & & \\
\hline
\end{tabular}

The Islamic religion was a highly common characteristic among the majority of respondents, as close to $95 \%$ reported being Muslim. This is expected because the main religion of the respondents' country of origin is Islam (see Table 8). 
Table 8. Respondents' Religion

\begin{tabular}{cccccc}
\hline & & Frequency & Percent & $\begin{array}{c}\text { Valid } \\
\text { Percent }\end{array}$ & $\begin{array}{c}\text { Cumulative } \\
\text { Percent }\end{array}$ \\
\cline { 2 - 6 } Muslim & 207 & 94.5 & 95.4 & 95.4 \\
\cline { 2 - 6 } & Christian & 3 & 1.4 & 1.4 & 96.8 \\
\cline { 2 - 6 } & non-religious & 6 & 2.7 & 2.8 & 99.5 \\
\cline { 2 - 6 } Missing & Other & 1 & .5 & .5 & 100.0 \\
\hline & & 217 & 99.1 & 100.0 & \\
\hline & & 219 & 100.0 & & \\
\hline
\end{tabular}

Table 9 shows that the marital status of most respondents was unmarried (59.2\%) whereas $39 \%$ were married.

Table 9. Respondents' Marital Status

\begin{tabular}{cccccc}
\hline & & Frequency & Percent & $\begin{array}{c}\text { Valid } \\
\text { Percent }\end{array}$ & $\begin{array}{c}\text { Cumulative } \\
\text { Percent }\end{array}$ \\
\hline \multirow{3}{*}{ Valid } & Single, Never Married & 129 & 58.9 & 59.2 & 59.2 \\
\cline { 2 - 6 } & Married & 85 & 38.8 & 39.0 & 98.2 \\
\cline { 2 - 6 } & Divorced & 3 & 1.4 & 1.4 & 99.5 \\
\cline { 2 - 6 } & Widower/Widow & 1 & .5 & .5 & 100.0 \\
\cline { 2 - 6 } Missing & Total & 218 & 99.5 & 100.0 & \\
\hline \multirow{2}{*}{} & & 1 & .5 & & \\
\hline
\end{tabular}

The number of family members in the respondents ranged from small to medium, with most reporting less than four family members $(46.8 \%)$ and about $37 \%$ reporting a family of four to six (see Table 10). 
Table 10. Respondents' Family Size

\begin{tabular}{cccccc}
\hline & & Frequency & Percent & $\begin{array}{c}\text { Valid } \\
\text { Percent }\end{array}$ & $\begin{array}{c}\text { Cumulative } \\
\text { Percent }\end{array}$ \\
& Less than 4 & 96 & 43.8 & 46.8 & 46.8 \\
\cline { 2 - 6 } Valid & $4-6$ & 76 & 34.7 & 37.1 & 83.9 \\
\cline { 2 - 6 } & More than 6 & 33 & 15.1 & 16.1 & 100.0 \\
\cline { 2 - 6 } & Total & 205 & 93.6 & 100.0 & \\
\hline \multirow{2}{*}{ Missing } & & 14 & 6.4 & & \\
\hline & & 219 & 100.0 & & \\
\hline
\end{tabular}

The immigrants who participated in this study also showed a high level of education, as a large majority (78.4\%) had completed their university studies (see Table 11).

Table 11. Respondents' Highest Education Level

\begin{tabular}{|c|c|c|c|c|c|}
\hline & & Frequency & Percent & $\begin{array}{l}\text { Valid } \\
\text { Percent }\end{array}$ & $\begin{array}{l}\text { Cumulative } \\
\text { Percent }\end{array}$ \\
\hline \multirow{4}{*}{ Valid } & University & 171 & 78.1 & 78.4 & 78.4 \\
\hline & High School & 38 & 17.4 & 17.4 & 95.9 \\
\hline & $\begin{array}{l}\text { Less than High } \\
\text { School }\end{array}$ & 9 & 4.1 & 4.1 & 100.0 \\
\hline & Total & 218 & 99.5 & 100.0 & \\
\hline Missing & & 1 & .5 & & \\
\hline Total & & 219 & 100.0 & & \\
\hline
\end{tabular}

Slightly more than half $(52.5 \%)$ the participants were still students, indicating that even those who had finished their studies in their home country came to Malaysia for further studies. About $12 \%$ were unemployed, which may have impacted our study (see Table 12). 
Table 12. Respondents' Employment Status

\begin{tabular}{cccccc}
\hline & Frequency & Percent & $\begin{array}{c}\text { Valid } \\
\text { Percent }\end{array}$ & $\begin{array}{c}\text { Cumulative } \\
\text { Percent }\end{array}$ \\
\hline \multirow{3}{*}{ Valid } & Student & 115 & 52.5 & 52.5 & 52.5 \\
\cline { 2 - 6 } & Employee & 57 & 26.0 & 26.0 & 78.5 \\
\cline { 2 - 6 } & Self-Employed & 21 & 9.6 & 9.6 & 88.1 \\
\cline { 2 - 6 } & Unemployed & 26 & 11.9 & 11.9 & 100.0 \\
\cline { 2 - 6 } & Total & 219 & 100.0 & 100.0 & \\
\hline
\end{tabular}

Despite their high rate of academic attainment, their employment status appears to have affected the monthly income of this group of immigrants, since most of them were students. An important and interesting indicator of the respondent immigrants was than more than 85\% of them earned less than RM5,000 per month (see Table 13), which is less than the average Malaysian monthly income of RM5,228 for 2016 (The Star, 2017). This can be explained by the fact that most participants were either students or unemployed.

Table 13. Respondents' Monthly Income

\begin{tabular}{llcccc}
\hline & Frequency & Percent & $\begin{array}{c}\text { Valid } \\
\text { Percent }\end{array}$ & $\begin{array}{c}\text { Cumulative } \\
\text { Percent }\end{array}$ \\
\hline \multirow{5}{*}{ Valid } & RM 2000 and below & 93 & 42.5 & 45.1 & 45.1 \\
\cline { 2 - 6 } & RM 2001-3000 & 45 & 20.5 & 21.8 & 67.0 \\
\cline { 2 - 6 } & RM 3001-4000 & 24 & 11.0 & 11.7 & 78.6 \\
\cline { 2 - 6 } & RM 4001-5000 & 16 & 7.3 & 7.8 & 86.4 \\
\cline { 2 - 6 } & RM 5001 and above & 28 & 12.8 & 13.6 & 100.0 \\
\hline \multirow{2}{*}{ Missing } & Total & 206 & 94.1 & 100.0 & \\
\hline Total & 13 & 5.9 & & \\
\hline
\end{tabular}

\subsubsection{Awareness of Services}

Respondents' awareness of healthcare services is an important variable that may impact their satisfaction with healthcare in the host country; thus, it enhances the understanding of these immigrants. First, Table 14 shows that the largest proportion of immigrants (70.8\%) sought medical services only when sick, with only about $14 \%$ going periodically to check their health. 
Table 14. Respondents' Seeking of Healthcare Services

\begin{tabular}{llcccc}
\hline & Frequency & Percent & $\begin{array}{c}\text { Valid } \\
\text { Percent }\end{array}$ & $\begin{array}{c}\text { Cumulative } \\
\text { Percent }\end{array}$ \\
\hline \multirow{5}{*}{ No Visits } & 33 & 15.1 & 15.1 & 15.1 \\
\cline { 2 - 6 } & Only When Sick & 155 & 70.8 & 70.8 & 85.8 \\
\cline { 2 - 6 } & $\begin{array}{l}\text { For Sickness } \\
\text { Wellness Care }\end{array}$ & 31 & 14.2 & 14.2 & 100.0 \\
\cline { 2 - 6 } & & & & & \\
\hline
\end{tabular}

More shocking is the fact that more than half the respondents were not fully aware of where they can go when they need medical services (54\%) (see Table 15).

Table 15. Respondents' Awareness of Where to Go for Medical Services

\begin{tabular}{llcccc}
\hline & & Frequency & Percent & $\begin{array}{c}\text { Valid } \\
\text { Percent }\end{array}$ & $\begin{array}{c}\text { Cumulative } \\
\text { Percent }\end{array}$ \\
\hline & $\begin{array}{l}\text { I Know Exactly } \\
\text { Where to Go }\end{array}$ & 100 & 45.7 & 45.9 & 45.9 \\
\cline { 2 - 6 } Valid & Not Sure & 118 & 53.9 & 54.1 & 100.0 \\
\cline { 2 - 6 } & Total & 218 & 99.5 & 100.0 & \\
\hline Missing & 1 & .5 & & \\
\hline Total & 219 & 100.0 & & \\
\hline
\end{tabular}

Another important statistic emerged regarding respondents' awareness of the procedures and costs of admission in Malaysian hospitals, both public and private (see Table 16). Their answers indicated a generally weak level of knowledge about these important details, as the majority of respondents (close to 70\%) said they are 'not sure'. This obvious lack of awareness may have a significant impact on the satisfaction of these immigrants with Malaysian healthcare services. 
Table 16. Respondents' Awareness of Procedures and Costs of Hospital Admission

\begin{tabular}{llcccc}
\hline & & Frequency & Percent & $\begin{array}{c}\text { Valid } \\
\text { Percent }\end{array}$ & Cumulative Percent \\
\hline \multirow{2}{*}{ Valid } & Yes, I know & 68 & 31.1 & 31.2 & 31.2 \\
\cline { 2 - 6 } & Not sure & 150 & 68.5 & 68.8 & 100.0 \\
\cline { 2 - 6 } & Total & 218 & 99.5 & 100.0 & \\
\hline Missing & & 1 & .5 & & \\
\hline Total & & 100.0 & & \\
\hline
\end{tabular}

Finally, Table 17 depicts respondents' awareness of health insurance, which is now an important component of healthcare in many countries around the world. The extent to which immigrants understand their health insurance, as well as how to use and benefit from it, is crucial, especially because they have paid a substantial amount for it. The results, however, were negative in this regard, with a majority of participants $(44.7 \%)$ claiming not to understand how to use their health insurance and only a third saying the opposite.

Table 17. Respondents' Awareness of Health Insurance and How to Use It

\begin{tabular}{clcccc}
\hline & Frequency & Percent & $\begin{array}{c}\text { Valid } \\
\text { Percent }\end{array}$ & $\begin{array}{c}\text { Cumulative } \\
\text { Percent }\end{array}$ \\
\hline \multirow{3}{*}{ Valid } & Yes & 65 & 29.7 & 29.7 & 29.7 \\
\cline { 2 - 6 } & No & 98 & 44.7 & 44.7 & 74.4 \\
\cline { 2 - 6 } & I don't have health insurance & 56 & 25.6 & 25.6 & 100.0 \\
\cline { 2 - 6 } & Total & 219 & 100.0 & 100.0 & \\
\hline
\end{tabular}

\subsubsection{Proficiency in English and Malay Languages}

Language is one of the most vital factors affecting migrants to a country with a different spoken language. Not surprisingly, the vast majority of respondents (about 95\%) considered Arabic to be their mother tongue (see Table 18). 
Table 18. Respondents' Native Language

\begin{tabular}{llcccc}
\hline & & Frequency & Percent & Valid Percent & Cumulative Percent \\
\hline \multirow{3}{*}{ Valid } & Arabic & 206 & 94.1 & 94.9 & 94.9 \\
\cline { 2 - 6 } & Turkish & 2 & .9 & .9 & 95.9 \\
\cline { 2 - 6 } & Persian & 5 & 2.3 & 2.3 & 98.2 \\
\cline { 2 - 6 } & Other & 4 & 1.8 & 1.8 & 100.0 \\
\cline { 2 - 6 } & Total & 217 & 99.1 & 100.0 & \\
\hline Missing & \multicolumn{7}{c}{2} & .9 & & \\
\hline Total & 219 & 100.0 & & \\
\hline
\end{tabular}

On a positive note, almost all the participants (92.7\%) reported good or very good proficiency in English, which is widely spoken in Malaysia, especially in the capital city of Kuala Lumpur (see Table 19).

Table 19. Respondents' English Language Proficiency

\begin{tabular}{llcccc}
\hline & Frequency & Percent & $\begin{array}{c}\text { Valid } \\
\text { Percent }\end{array}$ & $\begin{array}{c}\text { Cumulative } \\
\text { Percent }\end{array}$ \\
\hline \multirow{4}{*}{ Valid } & Very Well & 121 & 55.3 & 55.5 & 55.5 \\
\cline { 2 - 6 } & Well & 81 & 37.0 & 37.2 & 92.7 \\
\cline { 2 - 6 } & Not Well & 10 & 4.6 & 4.6 & 97.2 \\
\cline { 2 - 6 } & Not At All & 6 & 2.7 & 2.8 & 100.0 \\
\cline { 2 - 6 } & Total & 218 & 99.5 & 100.0 & \\
\hline Missing & \multicolumn{7}{c}{1} & .5 & & \\
\hline Total & 219 & 100.0 & & \\
\hline
\end{tabular}

On the contrary, the respondents' proficiency in the Malay language, the official language of Malaysia, was not as good as in English. Most of them (56.2\%) stated they do not know the language at all, while only seven (3\%) respondents claimed to be very fluent in Malay (see Table 20). 
Table 20. Respondents' Malay Language Proficiency

Frequency Percent Valid Percent Cumulative Percent

\begin{tabular}{llcccc}
\hline & Very Well & 7 & 3.2 & 3.2 & 3.2 \\
\cline { 2 - 5 } Valid & 28 & 12.8 & 12.8 & 16.0 \\
\cline { 2 - 5 } & Not Well & 61 & 27.9 & 27.9 & 43.8 \\
\cline { 2 - 5 } & Not At All & 123 & 56.2 & 56.2 & 100.0 \\
\cline { 2 - 5 } & Total & 219 & 100.0 & 100.0 &
\end{tabular}

Notably, many of the respondents (65\%) mentioned facing issues with language and translation when they went to health centers (see Table 21).

Table 21. Respondents' Issues with Language and Translation in Health Facilities

\begin{tabular}{|c|c|c|c|c|c|}
\hline & & Frequency & Percent & $\begin{array}{c}\text { Valid } \\
\text { Percent }\end{array}$ & $\begin{array}{c}\text { Cumulative } \\
\text { Percent }\end{array}$ \\
\hline \multirow{4}{*}{ Valid } & Yes, I have & 49 & 22.4 & 22.4 & 22.4 \\
\hline & Yes, sometimes & 94 & 42.9 & 42.9 & 65.3 \\
\hline & No, everything is ok & 76 & 34.7 & 34.7 & 100.0 \\
\hline & Total & 219 & 100.0 & 100.0 & \\
\hline
\end{tabular}

\subsubsection{Legal Status}

The legal status of immigrants is critical to their access to and satisfaction with the healthcare provided to them in the host country. Indeed, illegal immigrants may lack access to their most basic human rights. Although there are quite a number of refugees and illegals in Malaysia, most of the participants in this study were legal residents in the country (88\%). The remaining respondents comprised one of three types, i.e., illegal, illegal refugee, or illegal asylum seeker (see Table 22). 
Table 22. Respondents' Legal Status

\begin{tabular}{|c|c|c|c|c|c|}
\hline & & Frequency & Percent & $\begin{array}{c}\text { Valid } \\
\text { Percent }\end{array}$ & $\begin{array}{c}\text { Cumulative } \\
\text { Percent }\end{array}$ \\
\hline \multirow{5}{*}{ Valid } & Legal & 193 & 88.1 & 88.9 & 88.9 \\
\hline & illegal & 4 & 1.8 & 1.8 & 90.8 \\
\hline & illegal \& Refugee & 13 & 5.9 & 6.0 & 96.8 \\
\hline & illegal \& Asylum seeker & 7 & 3.2 & 3.2 & 100.0 \\
\hline & Total & 217 & 99.1 & 100.0 & \\
\hline \multicolumn{2}{|l|}{ Missing } & 2 & .9 & & \\
\hline \multicolumn{2}{|l|}{ Total } & 219 & 100.0 & & \\
\hline \multirow{2}{*}{\multicolumn{6}{|c|}{$\begin{array}{l}\text { Next, immigrants are sensitive to the need for similar treatment as ordinary citizens with } \\
\text { regards to healthcare access. This is clearly a significant reflection of their satisfaction with } \\
\text { these services. Table } 23 \text { shows that } 64.4 \% \text { of the respondents feel that their status in Malaysia } \\
\text { either directly or indirectly impacts their access to healthcare services. } \\
\text { Table 23. Respondents' Perception of Residence Status's Effect on Access to Health Services }\end{array}$}} \\
\hline & & & & & \\
\hline & Fre & yency & Percent & $\begin{array}{c}\text { Valid } \\
\text { Percent }\end{array}$ & $\begin{array}{c}\text { Cumulative } \\
\text { Percent }\end{array}$ \\
\hline \multirow{4}{*}{ Valid } & Yes & 88 & 40.2 & 40.7 & 40.7 \\
\hline & Yes, sometimes & 51 & 23.3 & 23.6 & 64.4 \\
\hline & No & 77 & 35.2 & 35.6 & 100.0 \\
\hline & Total & 216 & 98.6 & 100.0 & \\
\hline Missing & & 3 & 1.4 & & \\
\hline Total & & 219 & 100.0 & & \\
\hline
\end{tabular}




\subsubsection{Duration of Residence in Malaysia}

Naturally, the longer one lives in any country, the better one's understanding and ability to adapt to the culture, the new environment, and the regulations and laws of that country. Most of the immigrants in our study appeared to be new arrivals, as the results showed that about $85 \%$ had lived in Malaysia for one to five years while only $4.6 \%$ had exceeded 10 years of residence (see Table 24). This confirms that Malaysia has recently become a desirable destination because of the many facilities offered to Middle Eastern immigrants with regard to visa procedures.

Table 24. Respondents' Duration of Residence

\begin{tabular}{llcccc}
\hline & & Frequency & Percent & Valid Percent & Cumulative Percent \\
\hline \multirow{5}{*}{ Valid } & 39 & 17.8 & 17.8 & 17.8 \\
\cline { 2 - 6 } & $1-5$ & 146 & 66.7 & 66.7 & 84.5 \\
\cline { 2 - 6 } & $6-10$ & 24 & 11.0 & 11.0 & 95.4 \\
\cline { 2 - 6 } & 10 and above & 10 & 4.6 & 4.6 & 100.0 \\
\cline { 2 - 6 } & Total & 219 & 100.0 & 100.0 & \\
\hline
\end{tabular}

\subsubsection{Culture}

Immigrants' culture often conflicts with that of their host country, which may affect their satisfaction with certain services provided in that country. From a medical point of view, many people use traditional medicine instead of commercial medicines, raising the issue of the potential unavailability of their countries' traditional medicines in the host country. The diversity of medical traditions in Malaysia, such as traditional Chinese acupuncture, Indian ayurvedic medicine, and Malay herbal medicine, seems to have alleviated cultural barriers with Middle Eastern countries, especially since most of these countries share common beliefs with the Malaysian people in terms of Islamic culture. Although $62 \%$ of respondents indicated their frequent use of traditional medicine (see Table 25), this does not cause any cultural contradictions with the healthcare they receive in Malaysia, as most immigrants reported no conflict between their original culture and the culture they encountered in Malaysia in relation to healthcare (see Table 26). 
Table 25. Respondents' Usage of Traditional Medicine

\begin{tabular}{llcccc}
\hline & Frequency & Percent & $\begin{array}{c}\text { Valid } \\
\text { Percent }\end{array}$ & $\begin{array}{c}\text { Cumulative } \\
\text { Percent }\end{array}$ \\
\hline \multirow{3}{*}{ Valid } & Yes, always & 38 & 17.4 & 17.4 & 17.4 \\
\cline { 2 - 6 } & Yes, sometimes & 97 & 44.3 & 44.5 & 61.9 \\
\cline { 2 - 6 } & No, at all & 83 & 37.9 & 38.1 & 100.0 \\
\cline { 2 - 6 } Missing & Total & 218 & 99.5 & 100.0 & \\
\hline Total & & 1 & .5 & & \\
\hline
\end{tabular}

Table 26. Respondents' Perception of Cultural Conflict with Malaysian Healthcare

\begin{tabular}{cccccc}
\hline & Frequency & Percent & $\begin{array}{c}\text { Valid } \\
\text { Percent }\end{array}$ & $\begin{array}{c}\text { Cumulative } \\
\text { Percent }\end{array}$ \\
\hline \multirow{2}{*}{ Valid } & Yes, most of time & 20 & 9.1 & 9.1 & 9.1 \\
\cline { 2 - 6 } & Yes, sometimes & 64 & 29.2 & 29.2 & 38.4 \\
\cline { 2 - 5 } & No & 135 & 61.6 & 61.6 & 100.0 \\
\cline { 2 - 5 } & Total & 219 & 100.0 & 100.0 & \\
\hline
\end{tabular}

\subsubsection{Satisfaction of Immigrants with Healthcare System}

A five-point Likert scale ( 1 = Strongly disagree to $5=$ Strongly agree $)$ was used to assess the degree of satisfaction of Middle Eastern immigrants with the Malaysian healthcare system. Table 27 offers a more comprehensive idea of the participants' views. The overall mean value of 2.87 showed a moderate satisfaction level, with a slight tendency towards dissatisfaction $(S D=1.157)$. Of the 10 statements, only three indicated respondents' satisfaction, with mean values above the average. They were about doctors and staff helping patients and answering their questions $(M=3.26, S D=1.235)$, doctors spending plenty of time with patients $(M=$ 3.03, $S D=1.13)$, and friendly treatment from the doctors, which was the highest $(M=3.45$, $S D=1.156$ ).

On the other hand, the remaining seven statements received negative ratings. The most notable of these were participants' trust in the competence of doctors $(M=2.58, S D=1.107)$, the accessibility of government healthcare services $(M=2.63, S D=1.115)$, and the general 
satisfaction of respondents with the Malaysian healthcare system $(M=2.75, S D=1.173)$. Above all, the most obvious value was the participants' dissatisfaction with healthcare costs $(M=2.21, S D=1.235)$.

Table 27. Respondents' Level of Satisfaction with the Malaysian Healthcare System

\begin{tabular}{lcccc}
\hline & Valid & Missing & Mean & Std. Deviation \\
\hline $\begin{array}{l}\text { 1. I always get help and answers to all my } \\
\text { questions from staff and doctors when I go } \\
\text { to any health center. }\end{array}$ & 213 & 6 & 3.26 & 1.235 \\
\hline
\end{tabular}

2. I fully trust the competence of doctors

$\begin{array}{lll}215 & 4 & 2.58\end{array}$
and the quality of medical services provided in Malaysia.

3. I have no problem with healthcare costs. 215

4. It easy to access public healthcare $215 \quad 4 \quad 2.63$ services whenever I need.

5. It easy to access private healthcare services whenever I need.

$\begin{array}{llll}214 & 5 & 2.99 & 1.204\end{array}$

$\begin{array}{lllll}\text { 6. I think doctors' offices have everything } & 215 & 4 & 2.88 & 1.100\end{array}$
needed to provide complete medical care.

$\begin{array}{lllll}\text { 7. The office hours during which I can get } & 213 & 6 & 2.96 & 1.117\end{array}$
medical care are convenient for me.

8. The doctors treat me in a very friendly $\quad \begin{array}{llll}216 & 3 & 3.45 & 1.156\end{array}$ and courteous manner.

$\begin{array}{llllll}\text { 9. Doctors usually spend plenty of time } & 214 & 5 & 3.03 & 1.130\end{array}$ with me.

10. Overall, I am satisfied with the $216 \quad 3 \quad 2.75 \quad 1.173$ healthcare system in Malaysia. 


\subsection{Correlation Analysis}

Pearson's correlation analysis was employed to verify the relationships between the different variables. The linear relationships between the independent variables (gender, age, marital status, highest education level, employment status, monthly income, awareness of services, English and Malay language proficiency, legal status, duration of residence, and culture) and the dependent variable (level of satisfaction with healthcare system) were tested. For the dependent variable, we had to choose one of the statements from the scale that gave the best representation of our dependent variable. The item selected was "satisfaction with costs of healthcare" because of its extreme value and its ability to be an important predictor of satisfaction. The outcome of the correlation analysis is shown in Table 28.

Table 28. Results of Correlation Analysis

\section{Satisfaction of Immigrants with the} Healthcare system (SIwHS)

\begin{tabular}{lcc}
\hline & Coefficient (r) & Sig. (2-tailed) \\
\hline Gender & .056 & .415 \\
\hline Age & -.129 & .061 \\
\hline Marital Status & $-.157^{*}$ & .022 \\
\hline Highest Education Level & .072 & .293 \\
\hline Employment Status & -.088 & .196 \\
\hline Income & .047 & .510 \\
\hline Awareness of Services & $-.230^{* *}$ & .001 \\
\hline English Use and Proficiency & .044 & .524 \\
\hline Malay Use and Proficiency & $-.160^{*}$ & .019 \\
\hline Legal Status & -.080 & .247 \\
\hline Duration of Residence & .024 & .724 \\
\hline Culture & $-.151^{*}$ & .027 \\
\hline
\end{tabular}

* Correlation is significant at the 0.05 level (2-tailed)

** Correlation is significant at the 0.01 level (2-tailed)

Based on the results, immigrants' satisfaction with the healthcare system has a highly weak negative correlation with their marital status $(r=-0.157 ; p<0.05)$, Malay use and proficiency $(r=-0.160 ; p<0.05)$ and culture $(r=-0.151 ; p<0.05)$. It also has a weak negative correlation with immigrants' awareness of services $(r=-0.230 ; p<0.01)$. In addition, there are some interrelationships among the socioeconomic variables. For example, age and marital status have a moderate positive correlation with each other $(r=0.522 ; p<$ $0.01)$, while age also correlates weakly with highest education level $(r=-0.291 ; p<0.01)$ 
and employment status $(r=0.396 ; p<0.01)$. Highest education level revealed a weak correlation with English use and proficiency $(r=0.305 ; p<0.01)$ as well.

In summation, the above analysis showed that immigrants' satisfaction with the Malaysian healthcare system is correlated with their marital status, awareness of services, Malay use and proficiency, and culture. In terms of the hypotheses, this analysis supports the following:

- Marital status has an impact on Middle Eastern immigrants' satisfaction with the Malaysian healthcare system $(r=-0.157 ; p<0.05)$.

- Knowledge and understanding of the Malaysian healthcare system (medical insurance, for example) has an impact on Middle Eastern immigrants' satisfaction with Malaysian healthcare system $(r=-0.230 ; p<0.01)$.

- Malay language proficiency has an impact on Middle Eastern immigrants' satisfaction with the Malaysian healthcare system $(r=-0.160 ; p<0.05)$.

- Culture has an impact on Middle Eastern immigrants' satisfaction with the Malaysian healthcare system $(r=-0.151 ; p<0.05)$.

\subsection{Regression Analysis}

In order to overcome some limitations of the correlation analysis, multiple linear regression was performed to achieve the research objectives. Under this analysis, we attempted to examine the influence of a number of independent variables on our single dependent variable (SIwHS) as this method is one of the most useful in this regard (Pallant, 2010). Tables 29, 30, and 31 represent the linear regression analysis results.

Table 29. Multiple Regression Analysis (Model Summary ${ }^{\text {b) }}$

\begin{tabular}{cccc}
\hline $\mathbf{R}$ & R Square & Adjusted R Square & Std. Error of the Estimate \\
\hline $.383^{\mathrm{a}}$ & .147 & .091 & 1.191 \\
\hline
\end{tabular}

a. Predictors: (Constant), Culture, Highest education level, Employment status, Duration of residence, Gender, English use and proficiency, Legal status, Malay use and proficiency, Awareness of services, Income, Marital status, Age

b. Dependent Variable: SIwHS

The regression model contained 12 independent variables, which had a coefficient of multiple determinations (R2) equal to 0.147 (see Table 29). This means that $14.7 \%$ of the variance of satisfaction was explained by this combination of twelve independent variables. The remaining factors that influence the satisfaction of immigrants with the healthcare system were not included in this study.

Table 30 presents the results of the ANOVA test. The significance value of this test was 0.003 , which indicates that our independent variables were jointly significant in explaining the 
dependent variable. The $\mathrm{F}$ test returned a value of 2.624 for the satisfaction of immigrants with the healthcare system, which was highly significant (0.003).

Table 30. ANOVA Test Results

\begin{tabular}{lccccc}
\hline \multicolumn{5}{c}{ ANOVA $^{\mathbf{a}}$} \\
Model & Sum of Squares & df & $\begin{array}{c}\text { Mean } \\
\text { Square }\end{array}$ & F & Sig. \\
\hline Regression & 44.659 & 12 & 3.722 & 2.624 & $.003^{\mathrm{b}}$ \\
\hline Residual & 259.545 & 183 & 1.418 & & \\
\hline Total & 304.204 & 195 & & & \\
\hline
\end{tabular}

a. Dependent Variable: Satisfaction of immigrants with the healthcare system

b. Predictors: (Constant), Culture, Highest education level, Employment status, Duration of residence, Gender, English use and proficiency, Legal status, Malay use and proficiency, Awareness of services, Income, Marital status, Age

All coefficient values of the variables as well as the results of the t-test are shown in Table 31 . The t-test results declare that three independent variables, namely marital status, income, and awareness of services, were significant in determining immigrants' satisfaction with the healthcare system, with awareness of services having the strongest effect on satisfaction $(\beta=$ - 0.654). 
Table 31. Multiple Regression Analysis Results (Coefficients ${ }^{a}$ )

\begin{tabular}{|c|c|c|c|c|c|}
\hline \multirow{2}{*}{ Model } & \multicolumn{2}{|c|}{$\begin{array}{l}\text { Unstandardized } \\
\text { Coefficients }\end{array}$} & \multirow{2}{*}{$\begin{array}{c}\begin{array}{c}\text { Standardized } \\
\text { Coefficients }\end{array} \\
\text { Beta }\end{array}$} & \multirow{2}{*}{$\mathbf{t}$} & \multirow{2}{*}{ Sig. } \\
\hline & B & Std. Error & & & \\
\hline (Constant) & 3.934 & .735 & & 5.353 & .000 \\
\hline Gender & .168 & .180 & .066 & .937 & .350 \\
\hline Age & .003 & .142 & .002 & .019 & .985 \\
\hline Marital Status & -.432 & .192 & -.189 & -2.248 & .026 \\
\hline Highest Education Level & .064 & .199 & .026 & .321 & .748 \\
\hline Employment Status & -.038 & .097 & -.030 & -.391 & .696 \\
\hline Income & .132 & .066 & .151 & 1.986 & .049 \\
\hline $\begin{array}{l}\text { Awareness of the } \\
\text { services }\end{array}$ & -.654 & .186 & -.262 & -3.510 & .001 \\
\hline $\begin{array}{l}\text { English use and } \\
\text { proficiency }\end{array}$ & .229 & .139 & .124 & 1.649 & .101 \\
\hline $\begin{array}{l}\text { Malay use and } \\
\text { proficiency }\end{array}$ & -.099 & .110 & -.067 & -.905 & .367 \\
\hline Legal status & -.163 & .141 & -.084 & -1.158 & .248 \\
\hline Duration of residence & -.136 & .138 & -.074 & -.986 & .325 \\
\hline Culture & -.056 & .140 & -.030 & -.399 & .691 \\
\hline
\end{tabular}

a. Dependent Variable: Satisfaction of immigrants with the healthcare system 


\section{Macrothink}

\section{Discussion}

The conceptual framework of this research (see Figure 1) sought to determine, first, the satisfaction of Middle Eastern immigrants with the Malaysian healthcare system, and second, the key factors that impact their satisfaction. To answer the question "How satisfied are Middle Eastern immigrants with the services provided to them in Malaysian health facilities, both public and private?", the results confirmed a slight dissatisfaction with the level of healthcare in Malaysia. Notably, the greatest dissatisfaction was with healthcare costs, potentially due to immigrants' financial difficulties in their new host country. This is especially pertinent as most of the study's participants were students, while more than $85 \%$ of the respondents reported a monthly income of less than RM5,000, which is less than the average Malaysian's monthly income. It is also possible that the respondents find a stark difference between the healthcare costs of Malaysia and their country of origin.

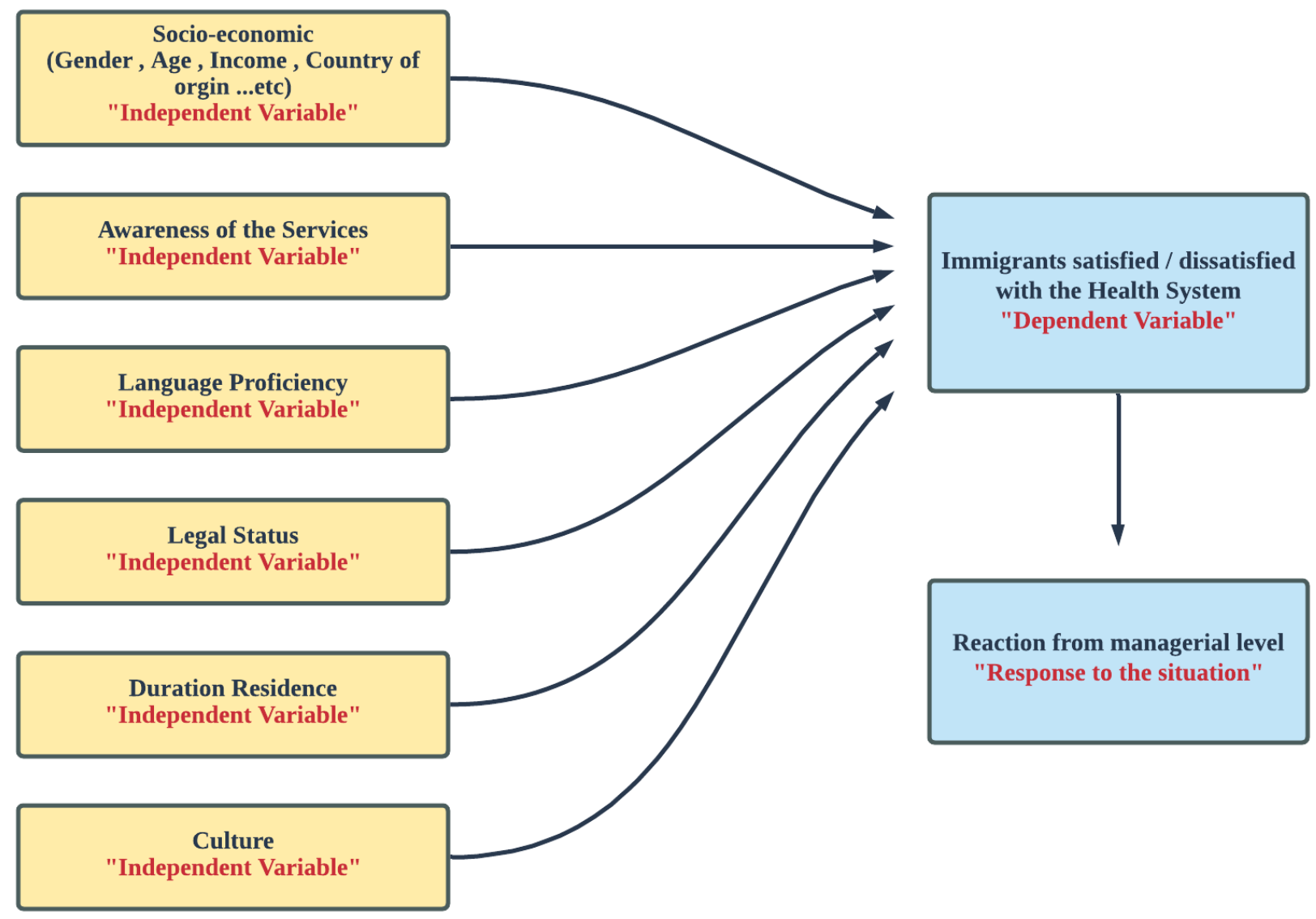

Figure 1. Conceptual framework

In achieving the second objective of this research to understand the main reasons behind the (dis)satisfaction of Middle Eastern immigrants with the Malaysian healthcare system, 12 independent variables were tested as predictors of immigrants' satisfaction with healthcare services. Of these, marital status, monthly income, awareness of services, Malay language proficiency, and culture were found to influence respondents' satisfaction. 
According to the Malaysian Healthcare Travel Council (2018), the healthcare industry will grow to reach RM 80 billion by 2020 from RM 52 billion at the end of 2017. This underscores the growing importance of the industry for both the public and private sectors. Unfortunately, there is a relative dissatisfaction among Middle Eastern immigrants with regard to the healthcare they receive in Malaysia, putting pressure on both sectors to take responsibility and work harder to meet the expectations of these immigrants.

This study showed that immigrants have limited awareness of the admission procedures of health centers or where they should go for medical assistance. The Ministry of Health should thus raise awareness among immigrants about local healthcare services. This can be done by providing adequate explanation or publishing guidelines at the entrances of health centers. Cost-effective approaches like social media sites can even be used to spread information, preferably in multiple languages for increased impact. The statistics of this study also indicate that, generally, the monthly income of most immigrants does not exceed RM 5000. This has placed financial pressure on them in terms of their ability to access and receive necessary medical treatment, especially in light of the high cost of health services in Malaysia. According to Willis Towers Watson (2017), there has been a consistent increase in medical costs since 2016, resulting in the growth of Asia Pacific countries as a whole. This has clearly affected the satisfaction of immigrants with healthcare costs, more so since most immigrants are students or even refugees who cannot work legally. Programs should be implemented to reduce the financial burden of students or refugees in cooperation with NGOs. Donors from private companies or United Nations organizations can also provide funding or small loans to help immigrants afford healthcare costs in critical health situations. For instance, in Austria, migrant, refugee, and asylum-seeking women are provided health support services in relevant foreign languages for free, including services for children and women affected by domestic and sexual violence (World Health Organization, 2018). Another initiative from Germany is the pilot project called Pregnancy and Flight, which targets pregnant refugee women in need. The helpline is available in 17 languages and focuses on pregnant refugees' special needs for support and assistance (World Health Organization, 2018).

As noted earlier, private insurance companies, hospitals, health clinics, and chain pharmacies should pay more attention to the growing target market of Middle Eastern immigrants by applying marketing plans and tools that are slightly different from those targeting Malaysians. First, the language factor must be taken seriously in all marketing processes, which will effectively increase awareness among immigrants. For example, insurance companies can explain their plans, benefits, and usage of their insurance cards in multiple languages (e.g. Arabic and Persian) on their website in addition to creating some explanatory videos in languages. Next, it should be noted that individuals are active representatives who build and rebuild the cultural forms that shape their opinions and actions (Kilduf \& Corley, 1999). In other words, it is important to conduct studies on the culture and traditions of immigrants because of the significance of the diaspora of home countries' culture and its role in affecting the way immigrants think and react towards a different culture in the host country. More research in this area will bestow a greater opportunity to understand this category of 
customers and the possibility of attracting them through customized promotion campaigns tailored to elements of their cultural heritage.

Finally, given that the language factor may remain one of the most important factors for immigrants around the world, it may affect other factors, such as awareness and access. This study found a significant result in this regard, where more than $65 \%$ of the respondents expressed language difficulties in health centers. Therefore, we recommend providing translators in health centers and hospitals, both public and private, who can be of assistance when needed.

\section{Limitations of the Study}

There are a few limitations that could have affected this study's outcomes. First, although the sample targeted for this research were immigrants from Arab countries and other Middle Eastern countries, such as Turkey and Iran, the number of participants from the latter two countries was limited, with only six participants. This makes it difficult to generalize the results to these two countries, especially since there are differences in language and culture with Arab countries, which received the larger number of participants.

Second, this research is a cross-sectional study; thus, the views of Middle Eastern immigrants about the Malaysian healthcare system were studied at a specific point in time regardless of their length of residence or experience with healthcare in the country. This prevents a comprehensive idea of the change in their views and the factors affecting them over time.

Finally, limited time was available to conduct this research, which affected the ability to pursue a greater number of respondents.

\section{Recommendations for Future Studies}

Based on the limitations mentioned above, some recommendations can be made to future researchers. First, this study was based on a broad sample of Middle Eastern immigrants. It is useful for researchers interested in this field to focus on a specific sample of only refugees or illegal immigrants, because this group may suffer from greater difficulties in the host country.

Second, the framework of this research can be extended to a larger sample while data can be collected from various sources in the healthcare industry, such as hospitals' client satisfaction surveys and third-party surveys and statistics.

Third, to gain a more accurate and deeper understanding of the factors influencing the satisfaction of immigrants with healthcare, qualitative research can preferably be conducted to examine these factors and identify practical solutions.

Finally, immigrants and their views vary greatly from country to country based on their culture, language, and expectations instilled in their country of origin. Therefore, it is useful to apply this study in different countries and among different categories of immigrants in these countries to provide valuable insights on this topic. 


\section{Conclusion}

To date, there has been limited information on the satisfaction of immigrants, in general, and Middle Eastern immigrants, in particular, with the Malaysian healthcare system. The few studies that have addressed this issue were on retired Japanese immigrants' healthcare in Malaysia (Kohno et al., 2016) and the health-related quality of life factors of Iraqi immigrants in Malaysia (Daher AM, Ibrahim, Daher TM \& Anbori, 2011). In addition, a recent qualitiative study in 2019 explored the most important barriers to healthcare access faced by migrant workers in Malaysia (Loganathan, Rui, Ng \& Pocock, 2019). Alternatively, our study presents a different view that has not been discussed previously in the Malaysian context. That is, it focused on immigrants' level of satisfaction not only from the humanity perspective, but also on the level of business and economy, by considering these immigrants as current and potential clients.

Overall, the current study has also shown results that are consistent with a range of previous studies from different countries, indicating a general trend toward lower levels of satisfaction among immigrants on host countries' healthcare. For example, a review, which included 28 studies, found that immigrants usually showed lower satisfaction levels with health services in western developed countries (Mastaki, 2010). Similirarly, African immigrants were mostly dissatisfied with local health services in Guangzhou, China (Lin et al., 2015). A recent study conducted in Finland also found that adults of Russian, Somali, and Kurdish origin were less satisfied than the general population with the health services they had used (Çilenti et al., 2021). On the other hand, some other studies have revealed findings contrary to our study. A Norwegian study demonstrated that Pakistani immigrants were adequately satisfied with the health care services provided to them in the country (Mohsin, 2017). Another study, which conducted with a sample consisted of 4083 respondents, indicated that immigrants have higher levels of satisfaction with healthcare in Qatar (Ali, Nikoloski \& Reka, 2015). Additionally, the findings of a recent study conducted in three different countries, Denmark, Germany, and the Netherlands, showed that immigrants expressed a higher level of satisfaction with public healthcare in these countries (Seibel \& Renema, 2021).

This study offered further insights and a deeper understanding of the impact of a number of factors on Middle Eastern immigrants' perceptions of the healthcare in Malaysia based on their experiences. For example, we revealed a slight dissatisfaction with the healthcare system and the role of the lack of awareness of health services in guiding these views, demonstrating the importance of this factor at the theoretical and practical levels. In addition to awareness of services, factors were like cost of services, marital status, monthly income, Malay proficiency, and culture were also considered to have a significant impact on immigrants' satisfaction.

\section{Acknowledgements}

We gratefully thank all the respondents who have participated in this research. 


\section{References}

Albin, B., Albertsson, M., Ekberg, J., \& Hjelm, K. (2005). Health and consumption of healthcare and social service among old migrants in Sweden. Primary Healthcare Research \& Development, 6(1), 37-45. https://doi.org/10.1191/1463423605pc212oa

Ali, F. M. H., Nikoloski, Z., \& Reka, H. (2015). Satisfaction and responsiveness with health-care services in Qatar-evidence from a survey. Health Policy, 119(11), 1499-1505. https://doi.org/10.1016/j.healthpol.2015.09.012

Boudreau, M. C., Gefen, D., \& Straub, D. W. (2001). Validation in Information Systems Research: A State-of-the-Art Assessment. MIS Quarterly, 25(1), 1-16. https://doi.org/10.2307/3250956

Carballo, M., \& Nerukar, A. (2001). Migration, refugees, and health risks. Emerging Infectious Diseases, 7(3 Suppl), 556-560. https://doi.org/10.3201/eid0707.017733

Çilenti, K., Rask, S., Elovainio, M., Lilja, E., Kuusio, H., Koskinen, S., Koponen, P., \& Castaneda, A. E. (2021). Use of Health Services and Unmet Need among Adults of Russian, Somali and Kurdish Origin in Finland. International Journal of Environmental Research and Public Health, 18(5), 2229. https://doi.org/10.3390/ijerph18052229

Daher, A. M., Ibrahim, H. S., Daher, T. M., \& Anbori, A. k. (2011). Health related quality of life among Iraqi immigrants settled in Malaysia. BMC Public Health, 11, 407. http://doi.org/10.1186/1471-2458-11-407

Dontsov, A. I., \& Zotova, O. Y. (2013). Reasons for Migration Decision Making and Migrants Security Notions. Procedia-Social and Behavioral Sciences, 86, 76-81. https://doi.org/10.1016/j.sbspro.2013.08.528

Gagnon, A., Merry, L., \& Robinson, C. (2001). A systematic review of refugee women's reproductive health. Refuge, 21, 6-17. https://doi.org/10.25071/1920-7336.21279

Glenn, D. (1992). Determining Sample Size. Program Evaluation and Organizational Development, IFAS, University of Florida. PEOD-6.

Grove, N. J., \& Zwi, A. B. (2006). Our health and theirs: forced migration, othering, and public health. Social Science and Medicine, 62, 1931-42. https://doi.org/10.1016/j.socscimed.2005.08.061

Ismayilova, L., Lee, H. N., Shaw, S., El-Bassel, N., Gilbert, L., Terlikbayeva, A., \& Rozental, Y. (2014). Mental Health and Migration: Depression, Alcohol Abuse, and Access to Healthcare among Migrants in Central Asia. Journal of Immigrant and Minority Health, 16(6), 1138-1148. http://doi.org/10.1007/s10903-013-9942-1

Kilduf, M., \& Corley, K., G. (1999). The Diaspora Effect: The Influence of Exiles on Their Cultures of Origin. M@n@gemen, 2(1), 1-12. Retrieved from http://www.management-aims.com/fichiers/publications/21Kilduff.pdf 
Kohno, A., Musa, G., Farid, N. D., Abdulaziz, N., Nakayama, T., \& Dahlui, M. (2016). Issues in healthcare services in Malaysia as experienced by Japanese retirees. BMC Health Services Research, 16, 167. http://doi.org/10.1186/s12913-016-1417-3

Kreps, G. L., \& Sparks, L. (2008). Meeting the health literacy needs of immigrant populations. Patient Education and Counseling, 71(3), 328-332.

https://doi.org/10.1016/j.pec.2008.03.001

Lian, O. S. (2005). Forskningsmessige utfordringer i studier av pasienttilfredshet [Methodological challenges in studies of patient satisfaction]. In Helsetjenesteforskning: perspektiver, metoder og muligheter [Health Services Research: perspectives, methods, and possibilities]. Edited by Foss, C., Ellefsen, B. Oslo: Universitetsforl, 144-156.

Lin, L., Brown, K. B., Yu, F., Yang, J., Wang, J., Schrock, J. M., ... Wong, F. Y. (2015). Health care experiences and perceived barriers to health care access: a qualitative study among African migrants in Guangzhou, Guangdong Province, China. Journal of Immigrant and Minority Health, 17(5), 1509-1517. https://doi.org/10.1007/s10903-014-0114-8

Loganathan, T., Rui, D., Ng, C. W., \& Pocock, N. S. (2019). Breaking down the barriers: Understanding migrant workers' access to healthcare in Malaysia. PloS one, 14(7), e0218669. https://doi.org/10.1371/journal.pone.0218669

Malaysia Healthcare Travel Council. (2018). Malaysia's healthcare industry to grow to RM80b by 2020. Retrieved from https://www.mhtc.org.my/malaysias-healthcare-industry-to-grow-to-rm80b-by-2020-frost-sul livan/

Malhotra, N. (2010). Marketing research: An applied orientation (6th ed.). Upper Saddle River: Pearson Education, Inc.

Mastaki, J. K. (2010). Migrant patients' satisfaction with health care services: a comprehensive review. Italian Journal of Public Health, 7(1), 69-81.

McMahon, E., Corcoran, P., Keeley, H., Cannon, M., Carli, V., Wasserman, C., \& Wasserman, D. (2017). Mental health difficulties and suicidal behaviours among young migrants: Multicenter study of European adolescents. BJPsych Open, 3(6), 291-299. https://doi.org/10.1192/bjpo.bp.117.005322

Mohsin, F. (2017). A study to observe the health care satisfaction among Pakistani immigrants in Norway (Master's thesis, Oslo and Akershus University College of Applied Sciences).

Moullan, Y., \& Jusot, F. (2014). Why is the 'healthy immigrant effect' different between European countries? European Journal of Public Health, 24, Supplement 1, 80-86. Retrieved from https://doi.org/10.1093/eurpub/cku112

Pallant, J. (2010). SPSS survival manual: A step by step guide to data analysis using SPSS: 
Open University Press.

Pallant, J. (2011). SPSS survival manual (4th ed.). Crows Nest: Allen \& Unwin.

Pelletier-Fleury, N., \& Vaillant, M. (2013). British residents' views about general practice care in France - a telephone survey. BMC Health Services Research, 13(224). http://www.biomedcentral.com/1472-6963/13/224

Seibel, V., \& Renema, J. A. (2021). Migrants' and Natives' Attitudes toward Public Healthcare Provision in Denmark, Germany, and the Netherlands. International Journal of Public Opinion Research, 33(1), 118-135. https://doi.org/10.1093/ijpor/edaa024

Small, R., Roth, C., Raval, M., Shafiei, T., Korfker, D., Heaman, M., McCourt, C., \& Gagnon, A. (2014). Immigrant and non-immigrant women's experiences of maternity care: a systematic and comparative review of studies in five countries. BMC Pregnancy and Childbirth, 14, 152. http://doi.org/10.1186/1471-2393-14-152

The Star. (2017). Malaysians' median monthly household income rises to RM5,228 in 2016. Retrieved from https://www.thestar.com.my/business/business-news/2017/10/09/ median-monthly-household-income-rises-in-2016/

United Nations High Commissioner for Refugees. (2020). Figures at a Glance in Malaysia. Retrieved from https://www.unhcr.org /en-my/figures-at-a-glance-in-malaysia

United Nations. (2018). International Migration Report 2017 - Highlights. UN iLibrary. https://doi.org/10.18356/5e2626a2-en

United Nations. (2019). International Migration 2019 Wall Chart. UN iLibrary. https://doi.org/10.18356/c36d3e0d-en

Willis Towers Watson. (2017). 2018 Global Medical Trends Survey Report. Retrieved from https://www.moncey-assurances.com/doc/TW-2018.pdf

World Health Organization. (2018). Health of refugees and migrants. Retrieved from https://www.who.int/docs/default-source/documents/publications/health-of-refugees-migrants -practices-euro-2018.pdf?sfvrsn=93dc0899_1\&download=true

Zeithaml, V., A., \& Bitner, M., J. (2000). Services Marketing: Integrating Customer Focus across the Firm. 2nd Edition, McGraw-Hill, Boston.

\section{Copyrights}

Copyright for this article is retained by the author(s), with first publication rights granted to the journal.

This is an open-access article distributed under the terms and conditions of the Creative Commons Attribution license (http://creativecommons.org/licenses/by/4.0/) 